\title{
Prevalence and correlates of adherence to the combined movement guidelines among Czech children and adolescents
}

\author{
Lukáš Rubín ${ }^{1,2}$, Aleš Gába ${ }^{1 *} \mathbb{B}$, Jan Dygrýn', Lukáš Jakubec ${ }^{1}$, Eliška Materová ${ }^{1}$ and Ondřej Vencálek ${ }^{3}$
}

\begin{abstract}
Background: There are limited studies on the prevalence of adherence to the combined guidelines for physical activity (PA), sedentary behavior, and sleep in children and adolescents. Moreover, little is known about correlates of adherence to the guidelines. Therefore, the main aim of this study is to examine the prevalence and identify the correlates of adherence to the combined movement guidelines among children and adolescents.

Methods: A total of 355 children aged 8-13 years (44\% boys) and 324 adolescents aged $14-18$ years (43\% boys) from the Czech Republic participated in this study. PA and sleep duration were estimated using multi-day 24-h raw data from wrist-worn accelerometers. Recreational screen time was parent proxy-reported in children and selfreported in adolescents. Seventeen potential correlates were grouped into three homogenous categories for biological and cognitive, behavioral, and family correlates. The multi-level multivariable logistic regression was applied to identify correlates of adherence to combined movement guidelines and to specific combinations of any of two recommendations.
\end{abstract}

Results: Approximately $6.5 \%$ of children and $2.2 \%$ of adolescents met all recommendations of the combined movement guidelines. In children, girls $(\mathrm{OR}=0.4 ; 95 \% \mathrm{Cl}=0.1-0.9)$ and participants with overweight or obese fathers $(\mathrm{OR}=0.3 ; 95 \% \mathrm{Cl}=0.1-0.7)$ had significantly lower odds of adherence to the combined movement guidelines. Additionally, children had higher odds of meeting specific combinations of two recommendations if they reported regular fruit and vegetable intake, participated in organized PA, or if their fathers had a university degree. Meanwhile, paternal overweight and obesity, and high sleep efficiency were associated with lower odds of meeting specific combinations of recommendations. In adolescents, sex, fruit and vegetable intake, organized PA, and active play were correlates of meeting specific combinations of any two recommendations.

Conclusions: A low proportion of children and adolescents met the combined movement guidelines and several correlates related to family were identified. Family is a key source of influence for healthy movement behaviors during childhood and adolescence.

Keywords: 24-h movement guidelines, Associations, Family, Physical activity, Screen time, Sedentary behavior, Sleep, Youth

\footnotetext{
* Correspondence: ales.gaba@upol.cz

${ }^{1}$ Faculty of Physical Culture, Palacký University Olomouc, třída Míru 117, 771

11 Olomouc, Czech Republic

Full list of author information is available at the end of the article
}

(c) The Author(s). 2020 Open Access This article is licensed under a Creative Commons Attribution 4.0 International License, which permits use, sharing, adaptation, distribution and reproduction in any medium or format, as long as you give appropriate credit to the original author(s) and the source, provide a link to the Creative Commons licence, and indicate if changes were made. The images or other third party material in this article are included in the article's Creative Commons licence, unless indicated otherwise in a credit line to the material. If material is not included in the article's Creative Commons licence and your intended use is not permitted by statutory regulation or exceeds the permitted use, you will need to obtain permission directly from the copyright holder. To view a copy of this licence, visit http://creativecommons.org/licenses/by/4.0/ The Creative Commons Public Domain Dedication waiver (http://creativecommons.org/publicdomain/zero/1.0/) applies to the data made available in this article, unless otherwise stated in a credit line to the data. 


\section{Introduction}

Physical activity (PA), sedentary behavior (SB), and sleep are key components of daily movement behaviors [1]. Ample evidence has confirmed the importance of all three behaviors (independently of each other) for physical, mental, and social health in children and adolescents [2-7]. Experts recommend that children and adolescents spend at least $60 \mathrm{~min}$ in moderate-tovigorous PA (MVPA) [8], accumulate no more than $2 \mathrm{~h}$ of recreational screen time (ST) [9], and get enough sleep (9-11 h for children and $8-10 \mathrm{~h}$ for adolescents) every day [10] to maximize their health.

A favorable health status is associated with meeting at least two movement behavior recommendations rather than with meeting single recommendation [11-14]. To encourage healthy movement behaviors, the first guidelines for children and adolescents combining PA, SB, and sleep was released in 2016 in Canada [15]. Other countries, such as Australia [16], Croatia [17], and Thailand [18], later joined this effort. The World Health Organization (WHO) is now preparing global combined movement guidelines for children and adolescents in accordance with the WHO Global action plan on physical activity 2018-2030 [19].

Despite the confirmed health benefits associated with meeting the recommendations for PA, SB, and sleep, worldwide adherence to the combined movement guidelines is low among children and adolescents [20-26]. Unfortunately, over the last decades, scientific evidence has documented a negative secular trend for engaging in regular $\mathrm{PA}$, limiting $\mathrm{SB}$, and obtaining adequate sleep [27-29]. Consequently, it is reasonable to predict that the adherence to the combined movement guidelines will continue to decline in the near future unless effective interventions are developed and implemented.

Because of the low effectivity of interventions focusing on supporting a single movement behavior [30, 31], implementation of intervention strategies targeting all movement behaviors is essential for mitigating or reversing the current trends. Thus, identification of correlates of the combined movement guidelines is necessary to design effective multicomponent interventions. Although correlates of single movement recommendation have been identified [2, 32-36], there is, to our knowledge, a lack of studies focused on identifying correlates of the combined movement guidelines. A few studies have been published recently [21-24], but they included study samples with a narrow age range, used self-reported measurements of movement behaviors, and/or had a limited number of examined correlates. Therefore, the main objectives of this study are (1) to examine the prevalence of adherence to the combined movement guidelines, and (2) to identify the correlates of such guidelines among Czech children and adolescents.

\section{Methods}

\section{Participants}

Children (8-13 years) and adolescents (14-18 years) were recruited from 11 elementary and secondary schools. Schools with a specific focus on sport and schools for pupils with special educational needs were not included. Participants were recruited to participate on a voluntary basis via information flyers that were distributed through the school staff after the school management approved the research. The main inclusion criteria were participant age and good health condition. The participants whose parents reported medical complications that could affect PA and sleep were excluded from study. A total of 907 children and adolescents were enrolled in this study. Of all initial participants, 228 were excluded because they voluntarily withdrew from the study or became ill $(n=45)$, provided incomplete data $(n=129)$, their data could not be assessed due technical failures $(n=17)$, or did not meet accelerometer wear time criteria $(n=37)$. Hence, the final sample consisted of 355 children (44\% boys) and 324 adolescents (43\% boys). The detailed characteristics of the participants are shown in Table 1.

\section{Physical activity and sleep}

PA and sleep were monitored using the wGT3X-BT and GT9X Link ActiGraph accelerometers (ActiGraph, Pensacola, FL, USA) worn by children and adolescents, respectively. The devices were initialized using the ActiLife software version 6.13.3 (ActiGraph, Pensacola, FL, USA), all three axes were used, and sampling interval was set to $100 \mathrm{~Hz}$. To limit reactivity, the displays of GT9X Link accelerometers were set to show only date and time and the official start of monitoring was the next full day following the day on which the devices were distributed. Participants wore the activity monitor on their non-dominant wrist for $24 \mathrm{~h}$ over 7 consecutive days. They were instructed to remove the device only for swimming and bathing.

Raw accelerometer data were analyzed using the Rpackage GGIR version 1.10-7. Time spent in MVPA was estimated using the Hildebrand's cut points for the Euclidian Norm Minus One metric [37]. Sleep duration (difference between sleep onset and waking up time) was calculated using the heuristic van Hees algorithm guided by participants' sleep logs [38]. Sleep efficiency was calculated as the ratio of time spent in sustained inactivity periods divided by sleep duration. Only data from participants who had worn the accelerometer for at least $16 \mathrm{~h}$ per day for at least 4 days (including 1 weekend day) were included in the analyses. A more detailed description of PA and sleep assessment has been published elsewhere $[39,40]$. 
Table 1 Descriptive characteristics of children and adolescents

\begin{tabular}{|c|c|c|c|c|c|c|c|c|c|}
\hline & \multicolumn{4}{|c|}{$\begin{array}{l}\text { Children } \\
n=355\end{array}$} & \multicolumn{4}{|c|}{$\begin{array}{l}\text { Adolescents } \\
n=324\end{array}$} & \multirow[t]{2}{*}{$p$-value ${ }^{\mathrm{b}}$} \\
\hline & Mean & SD & Min & $\operatorname{Max}$ & Mean & SD & Min & Max & \\
\hline \multicolumn{10}{|l|}{ Personal data } \\
\hline Age (years) & 11.7 & 1.6 & 8.1 & 13.9 & 16.3 & 1.3 & 14.0 & 18.0 & $<0.001$ \\
\hline Height (cm) & 151.6 & 12.0 & 117.7 & 185.6 & 170.2 & 8.8 & 147.0 & 194.9 & $<0.001$ \\
\hline Weight (kg) & 43.6 & 11.3 & 17.8 & 79.4 & 63.0 & 11.6 & 41.5 & 120.8 & $<0.001$ \\
\hline BMI z-score & 0.24 & 1.13 & -3.35 & 3.32 & 0.20 & 0.99 & -2.83 & 3.49 & 0.587 \\
\hline \multicolumn{10}{|l|}{ Movement behaviors } \\
\hline MVPA (min/day) ${ }^{a}$ & 58.1 & 24.3 & 7.2 & 151.7 & 39.3 & 19.1 & 2.9 & 100.7 & $<0.001$ \\
\hline ST (h/day) & 3.0 & 1.8 & 0.1 & 11.9 & 2.8 & 2.1 & 0.1 & 12.9 & 0.206 \\
\hline Sleep duration (h/day) ${ }^{a}$ & 8.6 & 0.7 & 6.4 & 10.6 & 7.5 & 0.8 & 5.4 & 10.2 & $<0.001$ \\
\hline
\end{tabular}

BMI Body mass index, Max Maximum, Min Minimum, MVPA Moderate-to-vigorous physical activity, SD Standard deviation, ST Screen time

${ }^{a}$ Accelerometer-based 24 -h assessment; adjusted to $24 \mathrm{~h}$ before analysis

${ }^{\mathrm{b}}$ The differences between age categories were analyzed using the $t$-test for independent samples

\section{Screen time}

Recreational ST was self-reported. A parent proxy report was required in children aged 12 years and younger (i.e., those in the first stage of elementary school). Participants, their parents, or guardians answered the questions taken from the questionnaire of the international Health Behaviour in School-aged Children study [41] as follows: "About how many hours a day do you usually spend watching television, DVDs, videos (including YouTube or similar online service) in your free time on weekdays/ weekend days?" and "About how many hours a day do you usually spend playing games on a computer, games console (PlayStation, Xbox, etc.), smartphone, tablet or similar electronic device in your free time on weekdays/ weekend days?". Questions were separated for weekdays and weekend days. Nine different answers were available for each question (none, half an hour, 1, 2, 3, 4, 5, 6, and 7 or more hours a day). The validity and reliability of 7 day recall questions have been demonstrated in comparison with 7-day 24-h diaries both on weekdays and weekends [42]. Total amount of ST was calculated as the sum of weighted averages of ST during weekdays and weekend days.

\section{Adherence to the combined movement guidelines}

Participants adhere to the combined movement guidelines if they accumulate at least $60 \mathrm{~min}$ of MVPA per day for PA recommendation, $2 \mathrm{~h}$ or less of recreational ST per day for SB recommendation, and 9-11 h per day for children and $8-10 \mathrm{~h}$ per day for adolescents for sleep recommendation.

\section{Correlates}

Seventeen potential correlates were selected based on systematic reviews [2, 32-36] showing plausible associations with at least single recommendation included in the combined movement guidelines. Correlates were grouped into three categories: (1) biological and cognitive correlates, (2) behavioral correlates, and (3) family correlates. They were obtained through multiple research sources. Biological correlates except sex were measured directly using standard anthropometric measurements and the multi-frequency bioimpedance analyzer InBody 720 (InBody, Seoul, Korea). Cognitive and behavioral correlates were self-reported except for sleep efficiency, which was measured by accelerometry. Parent proxy report was required for participants aged 12 years and younger. Family correlates were reported by parents. The full list of correlates with information about their use in the analysis is displayed in Table 2.

\section{Procedure}

Data were collected from 2018 to 2019 during regular school weeks. Participants were given accelerometers in the classrooms and were instructed on how to wear them properly and how to complete relevant sleep logs. Participants and/or their parents or guardians were asked to fill in the questionnaires. Parents or guardians responded to family characteristic questions. Participants responded to the remaining questions (except children aged 12 years and younger where answering by parents was required). After 8 days, accelerometers, sleep logs, and questionnaires were collected.

\section{Statistical analyses}

Statistical analyses were conducted using the IBM SPSS Statistics version 23 (IBM, Armonk, NY, USA) and R version 3.4.2 ( $\mathrm{R}$ Foundation for Statistical Computing, Vienna, Austria). All analyses were performed separately for children and adolescents. The differences between children and adolescents were analyzed using the $t$-test 
Table 2 Potential correlates of meeting the combined movement guidelines

\begin{tabular}{|c|c|c|c|}
\hline & $\begin{array}{l}\text { Method of } \\
\text { measurement }\end{array}$ & Measurement/Question & Use in analysis \\
\hline \multicolumn{4}{|c|}{ Biological and cognitive } \\
\hline Sex & Self-reported & Sex. & $\begin{array}{l}\text { Binary variable: } \\
\text { girl }(1) \text { or boy }\left(0^{a}\right)\end{array}$ \\
\hline $\begin{array}{l}\text { School } \\
\text { achievement }\end{array}$ & Self-reported & $\begin{array}{l}\text { Did you pass with distinction on your final school report in the } \\
\text { previous school year? }\end{array}$ & Binary variable: yes $(1)$ or no $\left(0^{a}\right)$ \\
\hline Adiposity & $\begin{array}{l}\text { Device- } \\
\text { measured }\end{array}$ & Assessed by multi-frequency bioimpedance analysis. & $\begin{array}{l}\text { Re-coded as dichotomous: < } 85 \text { th percentile } \\
\left(1^{1}\right) \text { or } \geq 85 \text { th percentile }(0)\end{array}$ \\
\hline BMI z-score & $\begin{array}{l}\text { Anthropometric } \\
\text { measurement }\end{array}$ & $\begin{array}{l}\text { World Health Organization BMI z-score based on direct } \\
\text { measurement of body height and weight. }\end{array}$ & $\begin{array}{l}\text { Re-coded as dichotomous: }<1 \text { SD }\left(1^{\mathrm{a}}\right) \text { or } \\
\geq 1 \mathrm{SD}(0)\end{array}$ \\
\hline \multicolumn{4}{|l|}{ Behavioral } \\
\hline $\begin{array}{l}\text { Organized } \\
\text { PA }\end{array}$ & Self-reported & $\begin{array}{l}\text { About how many hours a week do you usually spend in } \\
\text { organized sport activities in your free time on weekdays/ } \\
\text { weekend days? }\end{array}$ & $\begin{array}{l}\text { Re-coded as dichotomous: } \geq 1 \mathrm{~h} \text { a week }(1) \text { or } \\
<1 \mathrm{~h} \text { a week }\left(0^{\mathrm{a}}\right)\end{array}$ \\
\hline Active play & Self-reported & $\begin{array}{l}\text { About how many hours a day do you usually spend in } \\
\text { unorganized PA in your free time on weekdays/weekend days? }\end{array}$ & $\begin{array}{l}\text { Re-coded as dichotomous: } \geq 2 \mathrm{~h} \text { a day }(1) \text { or } \\
<2 \mathrm{~h} \text { a day }\left(0^{\mathrm{a}}\right)\end{array}$ \\
\hline $\begin{array}{l}\text { AT to } \\
\text { school }\end{array}$ & Self-reported & $\begin{array}{l}\text { Check the prevailing mode (walk, bicycle, in-line, skateboard, car, } \\
\text { bus, train) of transportation on the way to school. }\end{array}$ & $\begin{array}{l}\text { Re-coded as dichotomous: } \geq 3 \text { days a week of } \\
\text { AT (1) or }<3 \text { days a week of AT }\left(0^{a}\right)\end{array}$ \\
\hline $\begin{array}{l}\text { AT from } \\
\text { school }\end{array}$ & Self-reported & $\begin{array}{l}\text { Check the prevailing mode (walk, bicycle, in-line, skateboard, car, } \\
\text { bus, train) of transportation on the way from school. }\end{array}$ & $\begin{array}{l}\text { Re-coded as dichotomous: } \geq 3 \text { days a week of } \\
\text { AT (1) or }<3 \text { days a week of AT }\left(0^{a}\right)\end{array}$ \\
\hline $\begin{array}{l}\text { Sleep } \\
\text { efficiency }\end{array}$ & $\begin{array}{l}\text { Device- } \\
\text { measured }\end{array}$ & $\begin{array}{l}\text { Measured by accelerometry and defined as the ratio of time } \\
\text { spent in sustained inactivity periods divided by sleep duration. }\end{array}$ & $\begin{array}{l}\text { Re-coded as dichotomous: } \geq 0.85(1) \text { or } \\
<0.85\left(0^{\mathrm{a}}\right)\end{array}$ \\
\hline $\begin{array}{l}\text { Fruit and } \\
\text { vegetable } \\
\text { intake }\end{array}$ & Self-reported & $\begin{array}{l}\text { About how many times a week do you usually eat or drink } \\
\text { a) fruits and b) vegetables? }\end{array}$ & $\begin{array}{l}\text { Re-coded as dichotomous: } \geq 1 \text { day a week ( } 1) \\
\text { or }<1 \text { day a week }\left(0^{2}\right) \text { for "a" and " } b \text { " }\end{array}$ \\
\hline $\begin{array}{l}\text { Unhealthy } \\
\text { snacking }\end{array}$ & Self-reported & $\begin{array}{l}\text { About how many times a week do you usually eat or drink } \\
\text { c) sweets (candy or chocolate), d) coke or other soft drinks } \\
\text { that contain sugar, and e) crisps, chips, salt sticks, etc.? }\end{array}$ & $\begin{array}{l}\text { Re-coded as dichotomous: } \geq 1 \text { day a week ( } 1) \\
\text { or }<1 \text { day a week }\left(0^{2}\right) \text { for " } c \text { ", " } d \text { " or " } e \text { " }\end{array}$ \\
\hline $\begin{array}{l}\text { Skipping } \\
\text { breakfast }\end{array}$ & Self-reported & $\begin{array}{l}\text { How often do you usually have breakfast (more than a glass } \\
\text { of milk or fruit juice) on weekdays/weekend days? }\end{array}$ & $\begin{array}{l}\text { Re-coded as dichotomous: < } 4 \text { days a week ( } 1) \\
\text { or } \geq 4 \text { days a week }\left(0^{a}\right)\end{array}$ \\
\hline \multicolumn{4}{|l|}{ Family } \\
\hline $\begin{array}{l}\text { Maternal } \\
\text { BMl }\end{array}$ & Parent-reported & Calculated from the self-reported body height and weight. & $\begin{array}{l}\text { BMl computed and re-coded as dichotomous: } \\
<25 \mathrm{~kg} / \mathrm{m}^{2}\left(1^{\mathrm{a}}\right) \text { or } \geq 25 \mathrm{~kg} / \mathrm{m}^{2}(0)\end{array}$ \\
\hline $\begin{array}{l}\text { Maternal } \\
\text { education }\end{array}$ & Parent-reported & Highest educational level. & $\begin{array}{l}\text { Re-coded as dichotomous: university and } \\
\text { higher education ( } 1) \text { or lower than university } \\
\text { education }\left(0^{a}\right)\end{array}$ \\
\hline $\begin{array}{l}\text { Paternal } \\
\text { BMl }\end{array}$ & Parent-reported & Calculated from the self-reported body height and weight. & $\begin{array}{l}\text { BMl computed re-coded as dichotomous: } \\
<25 \mathrm{~kg} / \mathrm{m}^{2}\left(1^{\mathrm{a}}\right) \text { or } \geq 25 \mathrm{~kg} / \mathrm{m}^{2}(0)\end{array}$ \\
\hline $\begin{array}{l}\text { Paternal } \\
\text { education }\end{array}$ & Parent-reported & Highest educational level. & $\begin{array}{l}\text { Re-coded as dichotomous: university and } \\
\text { higher education ( } 1) \text { or lower than university } \\
\text { education }\left(0^{\mathrm{a}}\right)\end{array}$ \\
\hline $\begin{array}{l}\text { Family } \\
\text { income }\end{array}$ & Parent-reported & $\begin{array}{l}\text { Is the total gross income of your household greater than } \\
48,000 \text { CZK per month (twice the median in Czechia)? }\end{array}$ & Binary variable: yes $(1)$ or no $\left(0^{\mathrm{a}}\right)$ \\
\hline
\end{tabular}

Parent proxy report was required for participants aged 12 years and younger

AT Active travel, BMI Body Mass Index, PA Physical activity, SD Standard deviation

aindicates reference category

for continuous variables and the chi-squared test for categorical variables.

Univariable analysis was conducted to examine associations between potential correlates and adherence to the combined movement guidelines and the specific combinations of any two recommendations. Binary logistic regression models were used because of the inherent nature of dependent variables ("0" for not meeting and
"1" for meeting the combined movement guidelines or combinations of any two recommendations). If an explanatory variable reached a less-strict criterion level of $p<0.1$, it was retained for further analysis to prevent the exclusion of potentially important correlates.

Multi-level multivariable logistic regression analysis was performed to identify correlates of adhering to the combined movement guidelines and of meeting combinations 
of any two recommendations. The potential correlates were included in the final models as fixed effects (Level 1), while the school location was considered a random effect (Level 2) in all mixed effects models. The necessity to include the factor of school location in the model was tested (by the likelihood-ratio test) and the factor was omitted whenever possible. Odds ratios (OR) and the 95\% confidence intervals $(\mathrm{CI})$ corresponding to the individual correlates as well as their significance were calculated. The forward selection method was used to set up the final model. The final models include all correlates whose omission would lead to a significant decrease in the Akaike information criterion. All statistical analyses were conducted at a significance level of $p<0.05$.

\section{Results}

Descriptive characteristics of the participants are shown in Table 1. Significant differences between children and adolescents were found for all movement behaviors except ST. Children engaged in more MVPA (18.8 min/ day) and slept longer (65.3 $\mathrm{min} /$ day) than adolescents $(p<0.001$ for both).

Figure 1 displays the prevalence of adherence to the combined movement guidelines or its specific combinations among children and adolescents. Children met the combined movement guidelines $(6.5 \%)$ in higher proportion $(p=0.006)$ compared with adolescents $(2.2 \%)$. More specifically, children have significantly higher adherence to the PA alone recommendation $(18.3$ vs $6.8 \% ; p<0.001)$ and the combination of PA and sleep recommendations (9.3 vs $2.5 \% ; p<0.001)$ than adolescents. Children met the ST alone $(11.0$ vs $26.2 \% ; p<0.001)$ and sleep alone (8.4 vs $14.2 \% ; p=0.018)$ recommendations in lower proportion than adolescents.

Tables 3 and 4 present the univariable analysis of associations between selected correlates and adhering to the combined movement guidelines or meeting any two recommendations. In the univariable analysis, twelve and six potential correlates reached a $p$-value of less than 0.1 for at least one combination of meeting movement recommendations in children and adolescents, respectively. These potential correlates were retained for further analysis.

The results of the multi-level multivariable analysis are shown in Table 5. In children, girls have significantly lower odds of adherence to the combined movement guidelines than boys $(\mathrm{OR}=0.4 ; 95 \% \mathrm{CI}=0.1-0.9)$. Children have significantly lower odds of adherence to the combined movement guidelines if their father is overweight or obese $(\mathrm{OR}=0.3 ; 95 \% \mathrm{CI}=0.1-0.7)$. Moreover, fruit and vegetable intake was associated with meeting the combinations of PA and ST $(\mathrm{OR}=2.0,95 \% \mathrm{CI}=1.1-$ 3.8), and ST and sleep recommendations (OR $=2.7,95 \%$ $\mathrm{CI}=1.3-5.5)$. Children that participated in organized PA
$(\mathrm{OR}=2.5,95 \% \mathrm{CI}=1.1-5.7)$ had higher odds of meeting the combination of $\mathrm{PA}$ and sleep recommendations, while children with high sleep efficiency $(\mathrm{OR}=0.4,95 \%$ $\mathrm{CI}=0.2-0.7$ ) had lower odds of meeting the same combination of recommendations. Paternal overweight and obesity was associated with lower odds of meeting the combinations of PA and ST $(\mathrm{OR}=0.5,95 \% \mathrm{CI}=0.4-$ 1.0 ), and ST and sleep recommendations (OR $=0.4,95 \%$ $\mathrm{CI}=0.2-0.8)$. Children had significantly higher odds of meeting the combination of PA and ST recommendations $(\mathrm{OR}=2.8,95 \% \mathrm{CI}=1.5-5.4)$ if their fathers had a university degree. In adolescents, those who reported regular fruit and vegetable intake had higher odds of meeting combination of $\mathrm{PA}$ and $\mathrm{ST}$ recommendations $(\mathrm{OR}=2.9,95 \% \mathrm{CI}=1.2-7.3)$. Adolescents who participated in organized PA and active play had higher odds of meeting the combinations of PA and ST $(\mathrm{OR}=2.9,95 \% \mathrm{CI}=1.1-9.3)$, and $\mathrm{PA}$ and sleep recommendations $(\mathrm{OR}=5.1,95 \% \mathrm{CI}=1.4-32.7)$, respectively. Adolescent girls have significantly higher odds of meeting the combinations of ST and sleep recommendations $(\mathrm{OR}=2.5,95 \% \mathrm{CI}=1.1-6.5)$ than adolescent boys.

\section{Discussion}

The present study revealed that a low proportion of Czech children and adolescents met the combined movement guidelines for PA, SB and sleep. Children met the combined movement guidelines in higher proportion compared with adolescents. We found that sex and paternal overweight and obesity were associated with adherence to the combined movement guidelines in children. Several correlates of combinations of any two recommendations have been identified for both age categories.

To the best of our knowledge, the accelerometrybased estimates of MVPA and sleep for evaluating adherence to movement guidelines were used in two studies that included children aged 9-11-years from 13 countries [20,21]. Compared with these countries, the proportion of Czech children who met the combined movement guidelines is below average, and this result is comparable to the prevalence in middle- (India and Kenya) and high-income (Finland) countries. However, the differences in adherence to movement guidelines between our study and the aforementioned studies should be interpreted with caution due to discrepancies in the ages of the participants and approaches used to obtain and analyze accelerometer data.

The novel finding of the present study is that adherence to the combined movement guidelines was sexspecific and paternal overweight and obesity lowered odds of meeting all movement behavior recommendations in children. To this date, only four studies were focused on correlates of the combined movement 


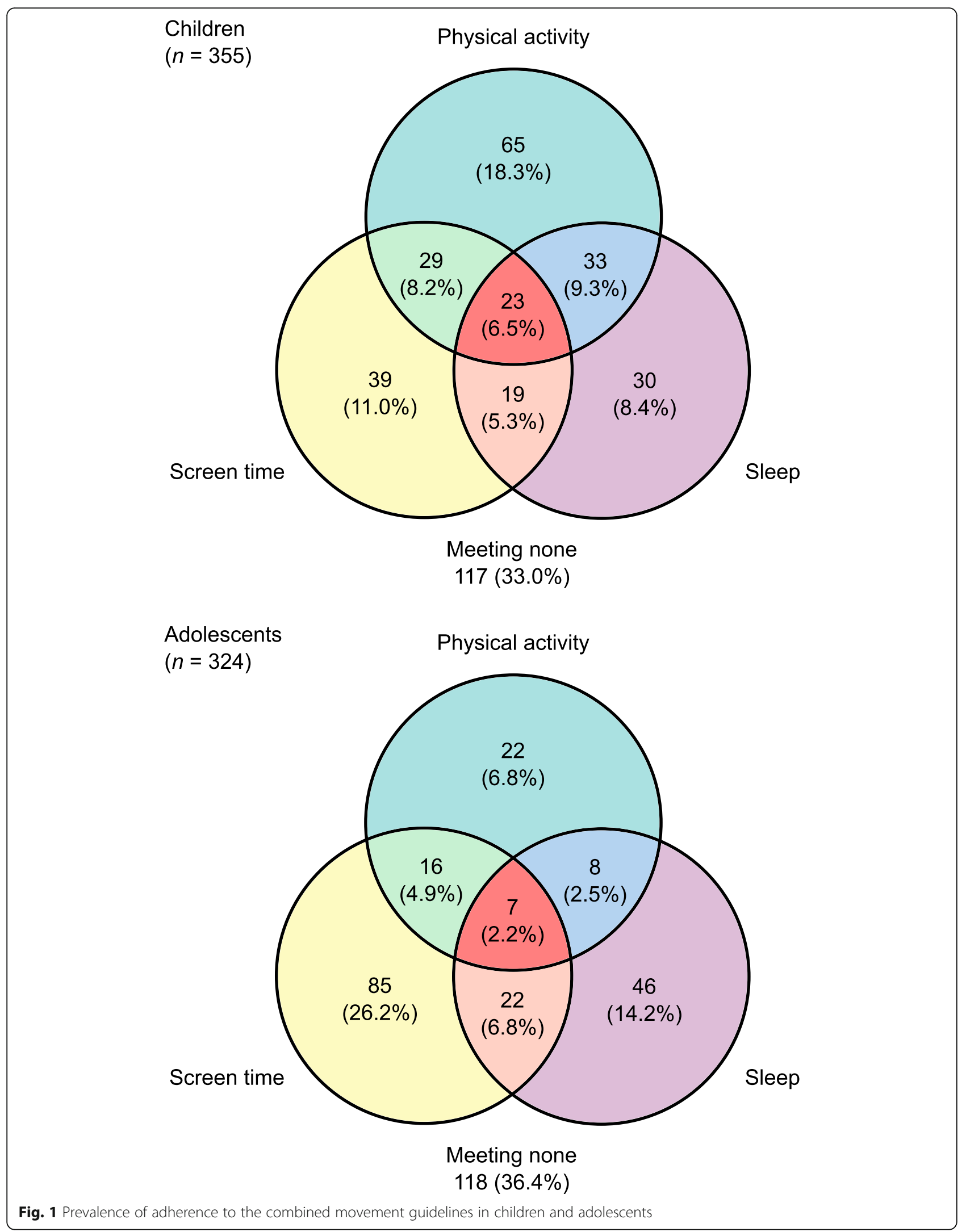


Table 3 Univariable analysis of correlates of meeting the combined movement guidelines in children $(n=355)$

\begin{tabular}{|c|c|c|c|c|c|c|c|c|c|c|c|c|c|}
\hline & \multirow[t]{2}{*}{$n(\%)^{a}$} & \multicolumn{3}{|c|}{$\mathrm{PA}+\mathrm{ST}+\mathrm{SL}$} & \multicolumn{3}{|c|}{$\mathrm{PA}+\mathrm{ST}$} & \multicolumn{3}{|c|}{$\mathrm{PA}+\mathrm{SL}$} & \multicolumn{3}{|c|}{$\mathrm{ST}+\mathrm{SL}$} \\
\hline & & OR & $95 \% \mathrm{Cl}$ & $p$-value & OR & $95 \% \mathrm{Cl}$ & $p$-value & OR & $95 \% \mathrm{Cl}$ & $p$-value & OR & $95 \% \mathrm{Cl}$ & $p$-value \\
\hline \multicolumn{14}{|l|}{ Biological and cognitive } \\
\hline Sex & $355(44)$ & 0.4 & $0.2-0.9$ & 0.037 & 0.8 & $0.5-1.5$ & 0.488 & 0.7 & $0.4-1.2$ & 0.183 & 0.9 & $0.5-1.8$ & 0.826 \\
\hline School achievement & $349(24)$ & 1.5 & $0.5-5.2$ & 0.507 & 2.1 & $1.0-5.4$ & 0.078 & 2.1 & $1.0-4.9$ & 0.077 & 2.5 & $1.0-7.4$ & 0.066 \\
\hline Adiposity & $355(86)$ & 0.3 & $0.0-1.3$ & 0.204 & 0.3 & $0.1-1.0$ & 0.082 & 0.6 & $0.2-1.4$ & 0.255 & 0.3 & $0.1-1.0$ & 0.089 \\
\hline BMl z-score & $355(75)$ & 0.3 & $0.0-1.0$ & 0.087 & 0.5 & $0.2-1.1$ & 0.103 & 0.6 & $0.3-1.3$ & 0.211 & 0.5 & $0.2-1.1$ & 0.108 \\
\hline \multicolumn{14}{|l|}{ Behavioral } \\
\hline Organized PA & $351(28)$ & 1.4 & $0.6-4.4$ & 0.496 & 1.2 & $0.6-2.4$ & 0.611 & 2.3 & $1.1-5.1$ & 0.035 & 1.8 & $0.8-4.2$ & 0.176 \\
\hline Active play & $355(25)$ & 1.2 & $0.5-3.7$ & 0.750 & 1.7 & $0.8-3.8$ & 0.195 & 1.6 & $0.8-3.5$ & 0.211 & 1.2 & $0.6-2.8$ & 0.622 \\
\hline AT to school & $342(52)$ & 0.8 & $0.3-1.8$ & 0.513 & 1.1 & $0.6-1.9$ & 0.833 & 1.1 & $0.6-1.9$ & 0.817 & 0.9 & $0.4-1.7$ & 0.702 \\
\hline AT from school & $338(41)$ & 0.6 & $0.2-1.3$ & 0.181 & 0.9 & $0.5-1.7$ & 0.716 & 0.9 & $0.5-1.6$ & 0.643 & 0.6 & $0.3-1.2$ & 0.119 \\
\hline Sleep efficiency & $343(40)$ & 0.5 & $0.2-1.3$ & 0.154 & 0.7 & $0.4-1.3$ & 0.262 & 0.3 & $0.2-0.6$ & $<0.001$ & 0.6 & $0.3-1.2$ & 0.119 \\
\hline Fruit and vegetable intake & $355(67)$ & 2.3 & $1.0-5.5$ & 0.052 & 2.1 & $1.2-3.8$ & 0.015 & 1.8 & $1.0-3.2$ & 0.050 & 2.5 & $1.3-4.8$ & 0.006 \\
\hline Unhealthy snacking & $355(58)$ & 1.3 & $0.5-3.0$ & 0.557 & 0.7 & $0.4-1.3$ & 0.246 & 2.3 & $1.3-4.1$ & 0.006 & 1.3 & $0.7-2.3$ & 0.431 \\
\hline Skipping breakfast & $350(81)$ & 0.2 & $0.0-1.0$ & 0.115 & 0.4 & $0.1-1.0$ & 0.089 & 0.7 & $0.3-1.6$ & 0.442 & 0.3 & $0.1-0.9$ & 0.068 \\
\hline \multicolumn{14}{|l|}{ Family } \\
\hline Maternal BMI & $338(66)$ & 0.5 & $0.2-1.4$ & 0.242 & 0.7 & $0.3-1.3$ & 0.256 & 0.8 & $0.4-1.4$ & 0.429 & 0.7 & $0.3-1.4$ & 0.284 \\
\hline Maternal education & $346(58)$ & 1.2 & $0.5-2.8$ & 0.706 & 2.0 & $1.1-3.7$ & 0.028 & 0.6 & $0.3-1.1$ & 0.081 & 1.2 & $0.6-2.4$ & 0.514 \\
\hline Paternal BMI & $328(27)$ & 0.3 & $0.1-0.7$ & 0.005 & 0.4 & $0.2-0.8$ & 0.010 & 0.6 & $0.4-1.2$ & 0.165 & 0.3 & $0.2-0.7$ & 0.002 \\
\hline Paternal education & $334(58)$ & 2.1 & $0.9-5.2$ & 0.097 & 3.1 & $1.7-5.9$ & 0.001 & 1.0 & $0.6-1.9$ & 0.912 & 1.9 & $1.0-3.9$ & 0.054 \\
\hline Family income & $284(36)$ & 2.0 & $0.7-7.4$ & 0.219 & 1.6 & $0.8-3.4$ & 0.196 & 1.4 & $0.7-3.0$ & 0.339 & 0.9 & $0.4-1.8$ & 0.691 \\
\hline
\end{tabular}

AT Active travel, BMI Body mass index, CI Confidence interval, OR Odds ratio, PA Physical activity, SL Sleep, ST Screen time

${ }^{a}$ Number of children included in the regression model and their proportion in the reference category

guidelines [21-24]. The parental weight status was analyzed only in the study by Manyanga and colleagues [21], who found no association with the adherence to the combined movement guidelines. However, previous studies have shown that parental weight status is associated with children's movement behaviors. Angoorani and colleagues [43] found higher odds of having low PA level and high ST in children whose parents were overweight or obese. One possible explanation for our results could be that parental obesogenic behaviors and shared home environment might be associated with movement behaviors. For example, an insufficient PA level of fathers is associated with a low PA level of their children [44] and/or presence of screens in bedroom is associated with greater ST and lower sleep duration [45]. For this reason, interventions to promote healthy movement behaviors during childhood need to involve both parents and should take into account the shared home environment.

The present study identified several correlates associated with meeting the specific combinations of any two recommendations. The participation in organized PA and active play was associated with meeting the combinations of PA and ST, and PA and sleep recommendations. This finding illustrates the compensatory change between the 24-h movement behaviors, which are typical examples of compositional data [1]. We can hypothesize that participation in organized and unorganized PA leads to an increase in overall PA, which results in compensatory changes in the remaining movement behaviors. Previous studies support this assumption by showing that a greater amount of time spent engaged in PA is associated with lower ST and longer sleep duration $[46,47]$. Furthermore, we found that fruit and vegetable intake, parental characteristics, and sleep efficiency were also associated with specific combinations of recommendations. Similar to the participation in organized PA and active play, these correlates are related to the family, which represents the key source of influence in lifestyle behaviors of children and adolescents [48]. The importance of family for meeting movement behavior recommendations in children and adolescents is supported by the recent study by Chen and colleagues [24], who found that parental educational level and family income are significantly positively associated with adherence to the combined movement guidelines.

Our study showed that the prevalence and correlates of adherence to the combined movement guidelines or meeting specific combinations of any two recommendations differ between children and adolescents. Similar to 
Table 4 Univariable analysis of correlates of meeting the combined movement guidelines in adolescents $(n=324)$

\begin{tabular}{|c|c|c|c|c|c|c|c|c|c|c|c|c|c|}
\hline & \multirow[t]{2}{*}{$n(\%)^{a}$} & \multicolumn{3}{|c|}{$\mathrm{PA}+\mathrm{ST}+\mathrm{SL}$} & \multicolumn{3}{|c|}{$\mathrm{PA}+\mathrm{ST}$} & \multicolumn{3}{|c|}{$\mathrm{PA}+\mathrm{SL}$} & \multicolumn{3}{|c|}{$\mathrm{ST}+\mathrm{SL}$} \\
\hline & & OR & $95 \% \mathrm{Cl}$ & $p$-value & OR & $95 \% \mathrm{Cl}$ & $p$-value & OR & $95 \% \mathrm{Cl}$ & $p$-value & OR & $95 \% \mathrm{Cl}$ & $p$-value \\
\hline \multicolumn{14}{|l|}{ Biological and cognitive } \\
\hline Sex & $324(43)$ & 4.6 & $0.6-38.9$ & 0.158 & 2.9 & $1.0-8.0$ & 0.041 & 0.6 & $0.2-1.8$ & 0.406 & 2.5 & $1.1-6.1$ & 0.038 \\
\hline School achievement & $320(66)$ & 5.0 & $1.1-35.0$ & 0.058 & 2.0 & $0.8-4.9$ & 0.116 & 1.7 & $0.6-4.9$ & 0.310 & 1.9 & $0.9-4.1$ & 0.103 \\
\hline Adiposity & $324(86)$ & 1.1 & $0.1-6.4$ & 0.956 & 1.0 & $0.2-2.9$ & 0.938 & 1.6 & $0.4-5.4$ & 0.461 & 0.7 & $0.2-2.2$ & 0.596 \\
\hline BMI z-score & $324(80)$ & 1.6 & $0.3-7.7$ & 0.573 & 0.8 & $0.2-2.3$ & 0.740 & 1.5 & $0.4-4.5$ & 0.515 & 0.4 & $0.1-1.3$ & 0.182 \\
\hline \multicolumn{14}{|l|}{ Behavioral } \\
\hline Organized PA & $323(43)$ & NA & NA & NA & 2.2 & $0.9-6.3$ & 0.102 & 3.1 & $1.0-13.9$ & 0.083 & 1.7 & $0.8-4.1$ & 0.187 \\
\hline Active play & $324(43)$ & 1.9 & $0.4-13.6$ & 0.437 & 1.0 & $0.4-2.4$ & 0.978 & 5.3 & $1.4-33.9$ & 0.031 & 1.5 & $0.7-3.5$ & 0.323 \\
\hline AT to school & $313(66)$ & 0.8 & $0.1-3.7$ & 0.765 & 1.1 & $0.4-2.7$ & 0.797 & 0.9 & $0.2-2.7$ & 0.810 & 1.2 & $0.5-2.6$ & 0.628 \\
\hline AT from school & $308(53)$ & 0.5 & $0.1-2.1$ & 0.342 & 1.0 & $0.4-2.3$ & 0.899 & 0.5 & $0.1-1.6$ & 0.247 & 0.9 & $0.4-2.0$ & 0.827 \\
\hline Sleep efficiency & $319(26)$ & 0.9 & $0.2-6.3$ & 0.892 & 0.8 & $0.3-2.2$ & 0.643 & 0.5 & $0.2-1.6$ & 0.225 & 0.7 & $0.3-1.8$ & 0.466 \\
\hline Fruit and vegetable intake & $324(67)$ & 5.3 & $1.1-37.2$ & 0.049 & 2.9 & $1.2-6.9$ & 0.016 & 2.4 & $0.9-7.1$ & 0.096 & 1.5 & $0.7-3.2$ & 0.318 \\
\hline Unhealthy snacking & $324(75)$ & NA & NA & NA & 0.8 & $0.3-2.1$ & 0.683 & 1.5 & $0.5-4.4$ & 0.467 & 1.1 & $0.5-2.6$ & 0.768 \\
\hline Skipping breakfast & $322(77)$ & 0.5 & $0.0-3.2$ & 0.574 & 0.5 & $0.1-1.4$ & 0.237 & 0.5 & $0.1-1.8$ & 0.359 & 1.1 & $0.4-2.5$ & 0.910 \\
\hline \multicolumn{14}{|l|}{ Family } \\
\hline Maternal BMI & $306(61)$ & NA & NA & NA & 0.7 & $0.3-1.6$ & 0.407 & 0.4 & $0.1-1.4$ & 0.190 & 0.5 & $0.2-1.2$ & 0.128 \\
\hline Maternal education & $316(60)$ & 1.1 & $0.2-5.2$ & 0.871 & 1.0 & $0.4-2.3$ & 0.940 & 0.7 & $0.2-2.2$ & 0.597 & 1.7 & $0.8-3.7$ & 0.175 \\
\hline Paternal BMI & $286(26)$ & 2.1 & $0.4-39.8$ & 0.499 & 0.5 & $0.2-1.2$ & 0.091 & 1.2 & $0.3-5.2$ & 0.836 & 0.9 & $0.4-2.2$ & 0.788 \\
\hline Paternal education & $295(58)$ & 1.8 & $0.4-9.5$ & 0.430 & 1.9 & $0.8-4.8$ & 0.161 & 1.4 & $0.5-4.1$ & 0.556 & 1.3 & $0.6-2.8$ & 0.499 \\
\hline Family income & $235(35)$ & 2.2 & $0.3-42.9$ & 0.490 & 0.8 & $0.3-2.4$ & 0.669 & 0.5 & $0.2-1.7$ & 0.267 & 1.4 & $0.5-4.0$ & 0.526 \\
\hline
\end{tabular}

NA indicate insufficient sample size for estimation

AT Active travel, BMI Body mass index, Cl Confidence interval, OR Odds ratio, PA Physical activity, SL Sleep, ST Screen time

${ }^{a}$ Number of adolescents included in the regression model and their proportion in the reference category

our study, Roberts et al. [49] found that children have significantly higher prevalence of meeting the combined movement guidelines compared with adolescents. These findings illustrate the age-related changes in movement behaviors that have been previously documented [50, 51]. We may have identified different types and number of correlates between children and adolescents because the family influence changes during the transition from childhood to adolescence. For example, adolescents have higher bed time autonomy than children [52], which could result in longer late-night ST and short sleep duration. Alternatively, adolescents may spend more of their free time outdoors without parental supervision, which could explain the association between adolescents' active play and meeting the specific combination of the combined movement guidelines.

The main strength of the present study is the multiday 24-h accelerometer-based assessment and raw data processing to estimate the amount of time spent in MVPA and sleep duration. Additionally, wrist-worn accelerometers provide more valid and comparable data as a result of increased participant compliance, reduction of non-wear time [53], and more precise estimates of sleep duration compared with hip-worn devices [54].
Another strength is the relatively large sample size that included participants with a wide age range. The use of multi-level multivariable regression could also be considered one of the strengths of this study.

This study has some limitations that must be mentioned. First, we were unable to determine the causality of the associations due to the cross-sectional design. Second, the low percentages of adherence to the combined movement guidelines and to any two of its components require cautious interpretation of $p$-values because all the tests performed are asymptotic and only approximate. Third, the associations found are limited to the list of potential correlates. It is necessary to mention that environmental correlates (except family environment) have not been examined in the present study. Future studies should examine more potential environmental correlates because, according to socio-ecological models, they are associated with movement behaviors. Fourth, the potential correlates included in this study were mostly self- or parent-reported. Fifth, recreational ST was parent proxy-reported in children and selfreported in adolescents which might produce different estimates of ST between age groups. Finally, the results are not fully generalizable to other young populations 
Table 5 Multi-level multivariable analysis of correlates of meeting the combined movement guidelines in children and adolescents

\begin{tabular}{|c|c|c|c|c|c|c|c|c|c|}
\hline & \multicolumn{4}{|l|}{$\begin{array}{l}\text { Children } \\
n=355\end{array}$} & & \multicolumn{4}{|c|}{$\begin{array}{l}\text { Adolescents } \\
n=324\end{array}$} \\
\hline & $\overline{n(\%)^{a}}$ & OR & $95 \% \mathrm{Cl}$ & $\overline{p \text {-value }}$ & & $\overline{n(\%)^{a}}$ & OR & $95 \% \mathrm{Cl}$ & $p$-value \\
\hline$\overline{P A}+S T+S L$ & & & & & $\mathrm{PA}+\mathrm{ST}+\mathrm{SL}$ & & & & \\
\hline Sex & $328(45)$ & 0.4 & $0.1-0.9$ & 0.037 & School achievement & $320(66)$ & 4.8 & $1.0-33.9$ & 0.066 \\
\hline Fruit and vegetable intake & $328(65)$ & 2.2 & $0.9-5.6$ & 0.079 & Fruit and vegetable intake & $320(67)$ & 5.1 & $1.1-36.0$ & 0.057 \\
\hline Paternal BMI & $328(27)$ & 0.3 & $0.1-0.7$ & 0.006 & & & & & \\
\hline $\mathrm{PA}+\mathrm{ST}$ & & & & & $\mathrm{PA}+\mathrm{ST}$ & & & & \\
\hline Fruit and vegetable intake & $325(65)$ & 2.0 & $1.1-3.8$ & 0.034 & Fruit and vegetable intake & $285(68)$ & 2.9 & $1.2-7.3$ & 0.019 \\
\hline Paternal BMI & $325(28)$ & 0.5 & $0.4-1.0$ & 0.034 & Organized PA & $285(43)$ & 2.9 & $1.1-9.3$ & 0.043 \\
\hline Paternal education & $325(58)$ & 2.8 & $1.5-5.4$ & 0.002 & Paternal BMI & $285(26)$ & 0.4 & $0.2-1.1$ & 0.066 \\
\hline $\mathrm{PA}+\mathrm{SL}^{\mathrm{b}}$ & & & & & $P A+S L$ & & & & \\
\hline School achievement & $335(23)$ & 2.1 & $0.8-5.4$ & 0.131 & Organized PA & $323(43)$ & 3.0 & $0.9-13.4$ & 0.096 \\
\hline Organized PA & $335(28)$ & 2.5 & $1.1-5.7$ & 0.038 & Active play & $323(43)$ & 5.1 & $1.4-32.7$ & 0.036 \\
\hline Sleep efficiency & $335(40)$ & 0.4 & $0.2-0.7$ & 0.003 & & & & & \\
\hline Unhealthy snacking & $335(58)$ & 1.9 & $1.0-3.8$ & 0.051 & & & & & \\
\hline $\mathrm{ST}+\mathrm{SL}$ & & & & & $\mathrm{ST}+\mathrm{SL}$ & & & & \\
\hline School achievement & $322(23)$ & 3.3 & $1.1-14.0$ & 0.060 & Sex & $320(43)$ & 2.5 & $1.1-6.5$ & 0.041 \\
\hline Fruit and vegetable intake & $322(65)$ & 2.7 & $1.3-5.5$ & 0.006 & School achievement & $320(66)$ & 1.9 & $0.9-4.1$ & 0.114 \\
\hline Paternal BMI & $322(28)$ & 0.4 & $0.2-0.8$ & 0.009 & & & & & \\
\hline
\end{tabular}

AT Active travel, BMI Body mass index, CI Confidence interval, OR Odds ratio, PA Physical activity, SL Sleep, ST Screen time

${ }^{a}$ Number of participants included in the model and their proportion in the reference category

${ }^{b}$ Response variable was associated with school location; multi-level regression model was used

because the correlates may not be similar across different cultures [55].

\section{Conclusions}

The present study revealed that a low proportion of Czech children and adolescents met the combined movement guidelines. Children have a higher prevalence of meeting all three recommendations included in the combined movement guidelines than adolescents. Sex of participants and paternal weight status were the only correlates associated with meeting the combined guidelines in children. Several correlates for specific combinations of any two recommendations have been found in both age categories. Family is related to all identified correlates and plays a crucial role in healthy lifestyle during childhood and adolescence. To design effective interventions supporting adherence to the combined movement guidelines among children and adolescents, family environment including parental characteristics should be considered.

\section{Abbreviations}

Cl: Confidence interval; MVPA: Moderate-to-vigorous physical activity; OR: Odds ratio; PA: Physical activity; SB: Sedentary behavior; SD: Standard deviation; ST: Screen time; WHO: World Health Organization

\section{Acknowledgements}

The authors are grateful to all the participants involved in this study.

\section{Authors' contributions}

$L R$ and $A G$ conceptualized and designed this study; $L R, A G, J D, L$, and EM collected the data; $L R$ and $A G$ prepared final dataset; $L R, A G$, and OV analyzed and interpreted the data; LR drafted the manuscript; AG provided intellectual role in improving the manuscript; JD, L, EM, and OV provided major roles in revising the manuscript. All authors read and approved the final manuscript.

\section{Funding}

This research was funded by the research grant of Czech Science Foundation (18-09188S) and by the research grant of Technical University of Liberec Student Grant Competition (SGS-2019-4090).

\section{Availability of data and materials}

The dataset analyzed during the current study is available in the Figshare repository, https://doi.org/10.6084/m9.figshare.12680855.

\section{Ethics approval and consent to participate}

The study was approved under reference number 19/2017 on March 16, 2017 by the Ethics Committee of the Faculty of Physical Culture, Palacký University Olomouc, which is governed by the ethical standards set out in the World Medical Association Declaration of Helsinki and its later amendments. Prior to the implementation of the research the participants' parents or guardians signed a written informed consent.

\section{Consent for publication}

Not applicable.

\section{Competing interests}

The authors declare that they have no competing interests.

\section{Author details}

${ }^{1}$ Faculty of Physical Culture, Palacký University Olomouc, trída Míru 117, 771

11 Olomouc, Czech Republic. ${ }^{2}$ Faculty of Science, Humanities and Education, 
Technical University of Liberec, Liberec, Czech Republic. ${ }^{3}$ Faculty of Science, Palacký University Olomouc, Olomouc, Czech Republic.

\section{Received: 27 July 2020 Accepted: 30 October 2020 Published online: 11 November 2020}

\section{References}

1. Pedišić Ž, Dumuid D, Olds TS. Integrating sleep, sedentary behaviour, and physical activity research in the emerging field of time-use epidemiology: definitions, concepts, statistical methods, theoretical framework, and future directions. Kinesiology. 2017:49(2):252-69.

2. Rhodes RE, Janssen I, Bredin SSD, Warburton DER, Bauman A. Physical activity: health impact, prevalence, correlates and interventions. Psychol Health. 2017;32(8):942-75.

3. Matricciani L, Paquet C, Galland B, Short M, Olds T. Children's sleep and health: a meta-review. Sleep Med Rev. 2019;46:136-50.

4. Carson V, Hunter S, Kuzik N, Gray CE, Poitras VJ, Chaput JP, et al. Systematic review of sedentary behaviour and health indicators in school-aged children and youth: an update. Appl Physiol Nutr Metab. 2016;41(6):S240-65.

5. Sampasa-Kanyinga H, Colman I, Goldfield GS, Janssen I, Wang J, Podinic I, et al. Combinations of physical activity, sedentary time, and sleep duration and their associations with depressive symptoms and other mental health problems in children and adolescents: a systematic review. Int J Behav Nutr Phys Act. 2020;17:72.

6. Chaput J-P, Gray CE, Poitras VJ, Carson V, Gruber R, Olds T, et al. Systematic review of the relationships between sleep duration and health indicators in school-aged children and youth. Appl Physiol Nutr Metab. 2016;41 (6Suppl. 3):S266-82.

7. Poitras VJ, Gray CE, Borghese MM, Carson V, Chaput J-P, Janssen I, et al. Systematic review of the relationships between objectively measured physical activity and health indicators in school-aged children and youth. Appl Physiol Nutr Metab. 2016;41(Suppl. 3):S197-239.

8. World Health Organization. Global recommendations on physical activity for health. 1st ed. Geneva: World Health Organization; 2010. p. 58.

9. Tremblay MS, LeBlanc AG, Janssen I, Kho ME, Hicks A, Murumets K, et al. Canadian sedentary behaviour guidelines for children and youth. Appl Physiol Nutr Metab. 2011;36(1):59-64.

10. Hirshkowitz M, Whiton K, Albert SM, Alessi C, Bruni O, DonCarlos L, et al. National Sleep Foundation's updated sleep duration recommendations: final report. Sleep Heal. 2015;1(4):233-43.

11. Hjorth MF, Chaput JP, Damsgaard CT, Dalskov SM, Andersen R, Astrup A et al. Low physical activity level and short sleep duration are associated with an increased cardio-metabolic risk profile: A longitudinal study in 8-11 year old Danish children. PLoS One. 2014;9(8):e104677.

12. Chaput J-P, Saunders TJ, Mathieu MË, Henderson M, Tremblay MS, O'Loughlin J, et al. Combined associations between moderate to vigorous physical activity and sedentary behaviour with cardiometabolic risk factors in children. Appl Physiol Nutr Metab. 2013;38(5):477-83.

13. Saunders TJ, Gray CE, Poitras VJ, Chaput J-P, Janssen I, Katzmarzyk PT, et al. Combinations of physical activity, sedentary behaviour and sleep: Relationships with health indicators in school-aged children and youth. Appl Physiol Nutr Metab. 2016;41(6 Suppl. 3):S283-93.

14. Li N, Zhao P, Diao C, Qiao Y, Katzmarzyk PT, Chaput J-P, et al. Joint associations between weekday and weekend physical activity or sedentary time and childhood obesity. Int J Obes. 2019;43(4):691-700.

15. Tremblay MS, Carson V, Chaput J-P, Connor Gorber S, Dinh T, Duggan M, et al. Canadian 24-hour movement guidelines for children and youth: An integration of physical activity, sedentary behaviour, and sleep. Appl Physiol Nutr Metab. 2016;4(6 Suppl. 3):S311-27.

16. Australian Government Department of Health. Australian 24-hour movement guidelines for children and young People (5 to 17 years): An integration of physical activity, sedentary behaviour, and sleep; 2017. p. 1.

17. Jurakić $D$, Pedišić Ž. Croatian 24-hour guidelines for physical activity, sedentary behaviour, and sleep: a proposal based on a systematic review of literature. Medicus. 2019;28(2):143-53.

18. Thai Ministry of Public Health. Thailand recommendations on physical activity, non-sedentary lifestyles, and sleeping; 2017. p. 1.

19. World Health Organization. Global action plan on physical activity 20182030: more active people for a healthier world. 1st ed. Geneva: World Health Organization; 2018. p. 101.
20. Roman-Viñas B, Chaput J-P, Katzmarzyk PT, Fogelholm M, Lambert EV, Maher $\mathrm{C}$, et al. Proportion of children meeting recommendations for 24 hour movement guidelines and associations with adiposity in a 12-country study. Int J Behav Nutr Phys Act. 2016;13:123.

21. Manyanga T, Barnes JD, Chaput J-P, Katzmarzyk PT, Prista A, Tremblay MS. Prevalence and correlates of adherence to movement guidelines among urban and rural children in Mozambique: a cross-sectional study. Int J Behav Nutr Phys Act. 2019;16:94.

22. Pearson N, Sherar LB, Hamer M. Prevalence and correlates of meeting sleep, screen-time, and physical activity guidelines among adolescents in the United Kingdom. JAMA Pediatr. 2019;173(10):993-4.

23. Lee E-Y, Carson V, Jeon JY, Spence JC, Tremblay MS. Levels and correlates of 24-hour movement behaviors among south Koreans: results from the Korea National Health and nutrition examination surveys, 2014 and 2015. J Sport Health Sci. 2019:8(4):376-85.

24. Chen S-T, Liu Y, Tremblay MS, Hong J-T, Tang Y, Cao Z-B, et al. Meeting 24hour movement guidelines: prevalence, correlates and the relationships with overweight and obesity among Chinese children and adolescents. J Sport Health Sci. 2020. https://doi.org/10.1016/j.jshs.2020.07.002. https:// www.sciencedirect.com/science/article/pii/S2095254620300892?via\%3Dihub.

25. Walsh JJ, Barnes JD, Cameron JD, Goldfield GS, Chaput J-P, Gunnell KE, et al. Associations between 24 hour movement behaviours and global cognition in US children: a cross-sectional observational study. Lancet Child Adolesc Heal. 2018;2(11):783-91.

26. Lien A, Sampasa-Kanyinga H, Colman I, Hamilton HA, Chaput J-P. Adherence to 24-hour movement guidelines and academic performance in adolescents. Public Health. 2020;183:8-14.

27. Matricciani L, Olds T, Petkov J. In search of lost sleep: secular trends in the sleep time of school-aged children and adolescents. Sleep Med Rev. 2012; 16(3):203-11.

28. Guthold R, Stevens GA, Riley LM, Bull FC. Global trends in insufficient physical activity among adolescents: a pooled analysis of 298 populationbased surveys with 1.6 million participants. Lancet Child Adolesc Heal. 2020; 4(1):23-35.

29. Kalman M, Inchley J, Sigmundova D, lannotti RJ, Tynjälä JA, Hamrik Z, et al. Secular trends in moderate-to-vigorous physical activity in 32 countries from 2002 to 2010: a cross-national perspective. Eur J Pub Health. 2015;25: $37-40$.

30. Metcalf B, Henley W, Wilkin T. Effectiveness of intervention on physical activity of children: systematic review and meta-analysis of controlled trials with objectively measured outcomes (EarlyBird 54). BMJ. 2012;345: e5888.

31. van Sluijs EMF, McMinn AM, Griffin SJ. Effectiveness of interventions to promote physical activity in children and adolescents: systematic review of controlled trials. BMJ. 2007:335(7622):703.

32. Bauman AE, Reis RS, Sallis JF, Wells JC, Loos RJF, Martin BW. Correlates of physical activity: why are some people physically active and others not? Lancet. 2012;380(9838):258-71.

33. Biddle SJH, Atkin AJ, Cavill N, Foster C. Correlates of physical activity in youth: a review of quantitative systematic reviews. Int Rev Sport Exerc Psychol. 2011:4(1):25-49.

34. Belmon LS, van Stralen MM, Busch V, Hamsen IA, Chinapaw MJM. What are the determinants of children's sleep behavior? A systematic review of longitudinal studies. Sleep Med Rev. 2019;43:60-70.

35. Bartel KA, Gradisar M, Williamson P. Protective and risk factors for adolescent sleep: a meta-analytic review. Sleep Med Rev. 2015;21:72-85.

36. Stierlin AS, De Lepeleere S, Cardon G, Dargent-Molina P, Hoffmann B, Murphy $\mathrm{MH}$, et al. A systematic review of determinants of sedentary behaviour in youth: a DEDIPAC-study. Int J Behav Nutr Phys Act. 2015;12:133.

37. Hildebrand M, van Hees VT, Hansen BH, Ekelund U. Age group comparability of raw accelerometer output from wrist- and hip-worn monitors. Med Sci Sports Exerc. 2014;46(9):1816-24.

38. van Hees VT, Sabia S, Anderson KN, Denton SJ, Oliver J, Catt M, et al. A novel, open access method to assess sleep duration using a wrist-worn accelerometer. PLoS One. 2015 Nov;10(11):e0142533.

39. Jakubec L, Gába A, Dygrýn J, Rubín L, Šimůnek A, Sigmund E. Is adherence to the 24-hour movement guidelines associated with a reduced risk of adiposity among children and adolescents? BMC Public Health. 2020;20: 1119

40. Gába A, Dygrýn J, Štefelová N, Rubín L, Hron K, Jakubec L, et al. How do short sleepers use extra waking hours? A compositional analysis of 24-h 
time-use patterns among children and adolescents. Int J Behav Nutr Phys Act. 2020;17:104.

41. Roberts C, Freeman J, Samdal O, Schnohr CW, de Looze ME, Nic Gabhainn $\mathrm{S}$, et al. The health behaviour in school-aged children (HBSC) study: methodological developments and current tensions. Int J Public Health. 2009;54(Suppl. 2):S140-50.

42. Schmitz KH, Harnack L, Fulton JE, Jacobs DR, Gao S, Lytle LA, et al. Reliability and validity of a brief questionnaire to assess television viewing and computer use by middle school children. J Sch Health. 2004;74(9):370-7.

43. Angoorani $\mathrm{P}$, Heshmat R, Ejtahed H-S, Motlagh ME, Ziaodini H, Taheri M, et al. The association of parental obesity with physical activity and sedentary behaviors of their children: the CASPIAN-V study. J Pediatr. 2018; 94(4):410-8.

44. Neshteruk CD, Nezami BT, Nino-Tapias G, Davison KK, Ward DS. The influence of fathers on children's physical activity: a review of the literature from 2009 to 2015. Prev Med (Baltim). 2017;102:12-9.

45. Falbe J, Davison KK, Franckle RL, Ganter C, Gortmaker SL, Smith L, et al. Sleep duration, restfulness, and screens in the sleep environment. Pediatrics. 2015;135(2):e367-75.

46. Lin Y, Tremblay MS, Katzmarzyk PT, Fogelholm M, Hu G, Lambert EV, et al. Temporal and bi-directional associations between sleep duration and physical activity/sedentary time in children: An international comparison Prev Med (Baltim). 2018;111:436-41

47. de Araújo LGM, Turi BC, Locci B, Mesquita CAA, Fonsati NB, Monteiro HL. Patterns of physical activity and screen time among Brazilian children. J Phys Act Health. 2018;15(6):457-61.

48. Rhodes RE, Guerrero MD, Vanderloo LM, Barbeau K, Birken CS, Chaput J-P, et al. Development of a consensus statement on the role of the family in the physical activity, sedentary and sleep behaviors of children and youth. Int J Behav Nutr Phys Act. 2020;17:74.

49. Roberts KC, Yao X, Carson V, Chaput J, Janssen I, Tremblay MS. Meeting the Canadian 24-hour movement guidelines for children and youth. Heal Reports. 2017;28(10):3-7.

50. Patte KA, Qian W, Leatherdale ST. Sleep duration trends and trajectories among youth in the COMPASS study. Sleep Heal. 2017;3(5):309-16.

51. Dalene KE, Anderssen SA, Andersen LB, Steene-Johannessen J, Ekelund U, Hansen $\mathrm{BH}$, et al. Secular and longitudinal physical activity changes in populationbased samples of children and adolescents. Scand J Med Sci Sports. 2018;28(1):161-71.

52. Tashjian SM, Mullins JL, Galván A. Bedtime autonomy and cellphone use influence sleep duration in adolescents. J Adolesc Health. 2019;64(1):124-30.

53. Fairclough SJ, Noonan R, Rowlands AV, Van Hees V, Knowles Z, Boddy LM. Wear compliance and activity in children wearing wrist- and hip-mounted accelerometers. Med Sci Sports Exerc. 2016;48(2):245-53.

54. Hjorth MF, Chaput J-P, Damsgaard CT, Dalskov S-M, Michaelsen KF, Tetens I, et al. Measure of sleep and physical activity by a single accelerometer: can a waist-worn Actigraph adequately measure sleep in children? Sleep Biol Rhythms. 2012;10(4):328-35.

55. Miller JM, Pereira MA, Wolfson J, Laska MN, Nelson TF, Neumark-Stzainer D. Are correlates of physical activity in adolescents similar across ethnicity/race and sex: implications for interventions. J Phys Act Health. 2019;16(12):1163-74.

\section{Publisher's Note}

Springer Nature remains neutral with regard to jurisdictional claims in published maps and institutional affiliations.

Ready to submit your research? Choose BMC and benefit from:

- fast, convenient online submission

- thorough peer review by experienced researchers in your field

- rapid publication on acceptance

- support for research data, including large and complex data types

- gold Open Access which fosters wider collaboration and increased citations

- maximum visibility for your research: over $100 \mathrm{M}$ website views per year

At BMC, research is always in progress.

Learn more biomedcentral.com/submissions 